\title{
UCRL-TR-228526
}

LAW RENCE LIVERMORE N A TIO N A L LABORATORY
Terahop and Lawrence Livermore National

LaboratoryStructural Fire RF

Testing

Peter Haugen, Garth Pratt

March 1, 2007 
This document was prepared as an account of work sponsored by an agency of the United States Government. Neither the United States Government nor the University of California nor any of their employees, makes any warranty, express or implied, or assumes any legal liability or responsibility for the accuracy, completeness, or usefulness of any information, apparatus, product, or process disclosed, or represents that its use would not infringe privately owned rights. Reference herein to any specific commercial product, process, or service by trade name, trademark, manufacturer, or otherwise, does not necessarily constitute or imply its endorsement, recommendation, or favoring by the United States Government or the University of California. The views and opinions of authors expressed herein do not necessarily state or reflect those of the United States Government or the University of California, and shall not be used for advertising or product endorsement purposes.

This work was performed under the auspices of the U.S. Department of Energy by University of California, Lawrence Livermore National Laboratory under Contract W-7405-Eng-48. 


\section{Terahop and Lawrence Livermore National Laboratory Structural Fire RF Testing}

Forsyth, Georgia 2/2007

Peter Haugen, Garth Pratt

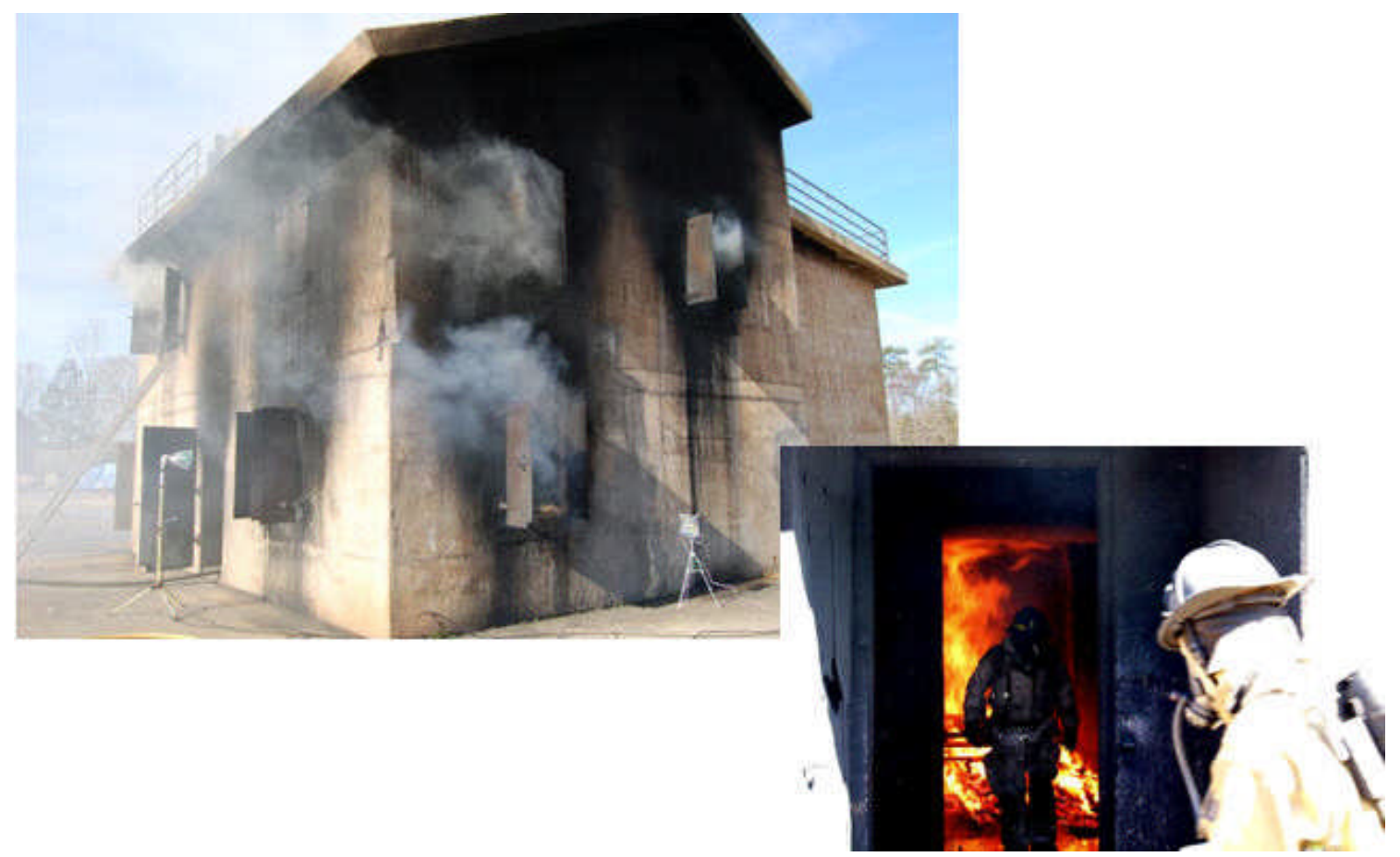

Figure 1: Georgia Public Safety Training Center's live fire training facility

\section{Table of Contents:}

BUILDING LAYOUT AND STRUCTURE:

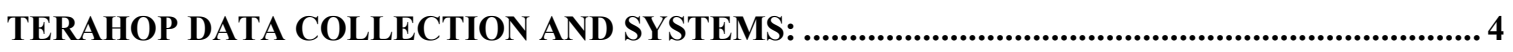

LAWRENCE LIVERMORE DATA COLLECTION:..................................................................... 6

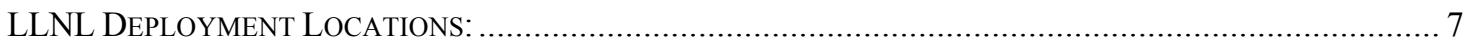

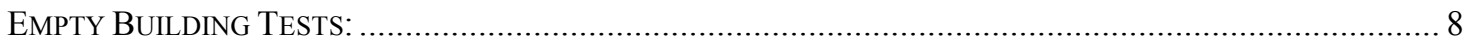

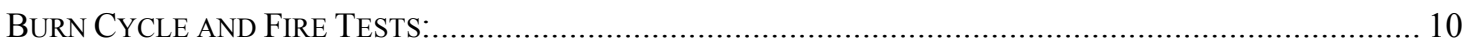

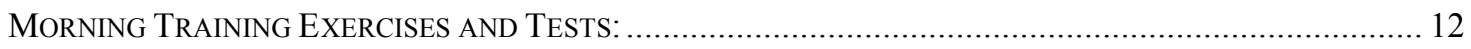

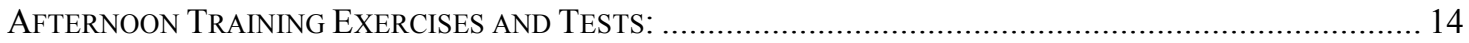
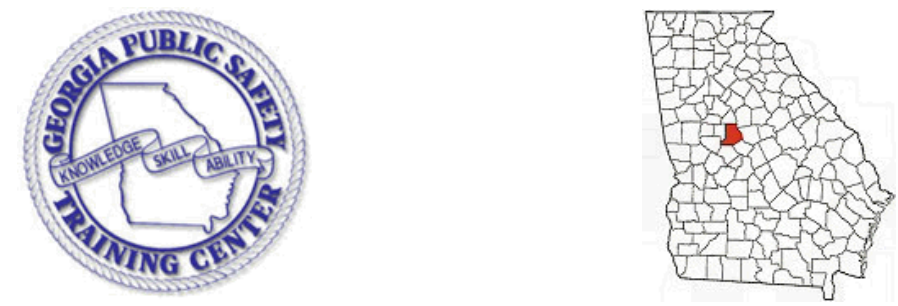


\section{Building Layout and Structure:}

The Georgia Public Safety Training Center's Live Fire Training Facility in Forsyth, GA is a three story structure constructed of rebar-reinforced concrete wall and floors. All the door and window coverings on the building are constructed of thick, plate metal to withstand the high temperatures generated inside the building during training exercises. All of the building's walls and floors are 1' thick, and regular concrete columns run up along the inside of the wall increasing the thickness to 20 " in those locations. A center concrete staircase divides the structure in half. For typical exercises, fires are started in the back right corner of the building on the first floor and in the front right corner on the second floor as shown in Figure 2 below.

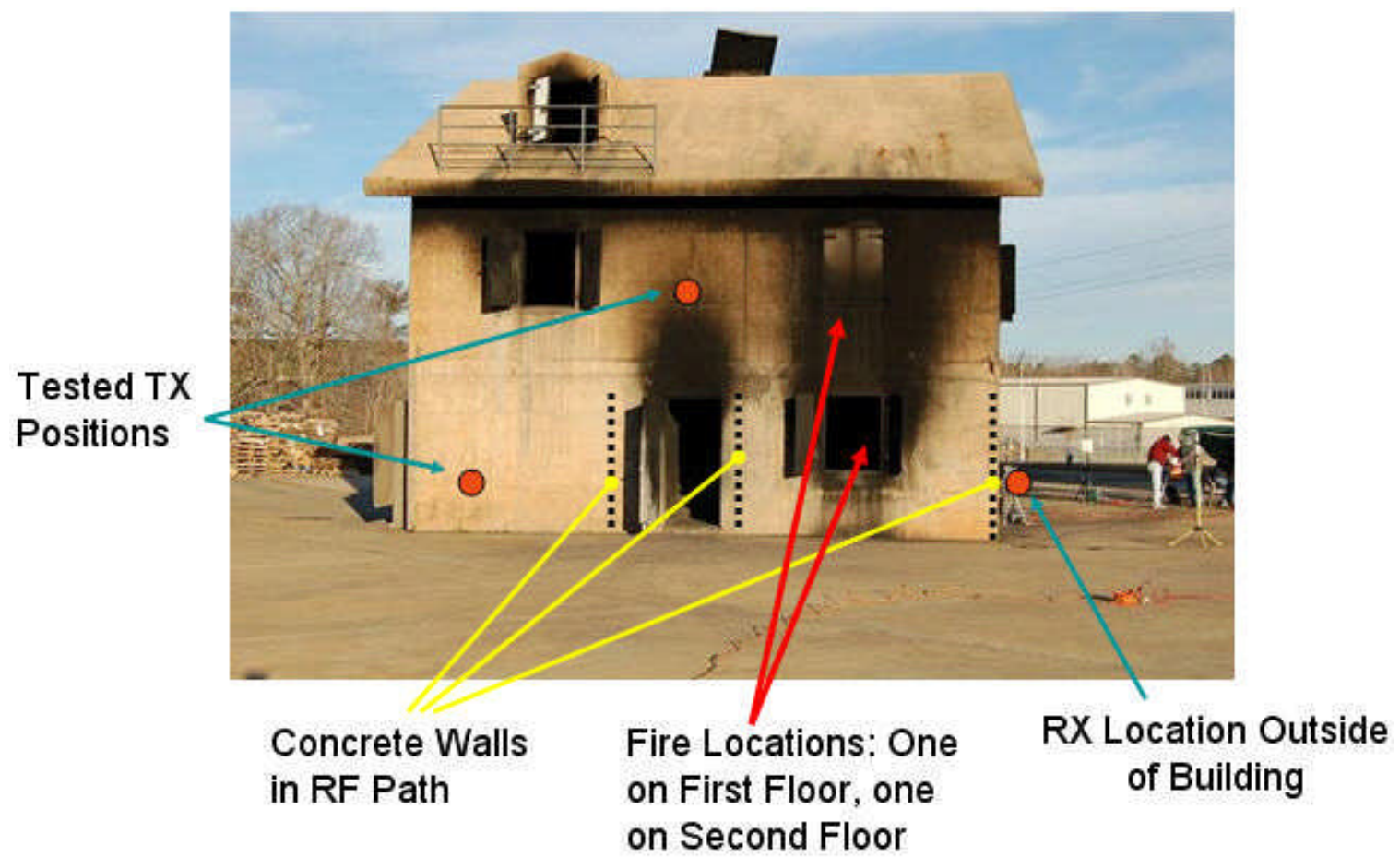

Figure 2: Live fire training facility, building features

Due to the high heat generated during these exercises, measured at $300^{\circ} \mathrm{F}$ on the floor and $700^{\circ} \mathrm{F}$ near the ceilings, there were limited locations at which equipment could be placed that did not incorporate heat shielding, such as the Lawrence Livermore National Laboratory's UWB system. However, upon inspection of the building, two preferable locations were identified in which equipment could be placed that would be protected from the temperature extremes generated by the fires. These locations are identified in Figure 2 as the tested TX locations. These were preferred locations because, while they protected the hardware from temperature extremes, they also force the RF transmission path through the building to cross very near the fire locations and anticipated plasma generation regions. Both of the locations listed in Figure 2 were tested by the UWB equipment and found to be suitable deployment locations to establish a solid RF link for
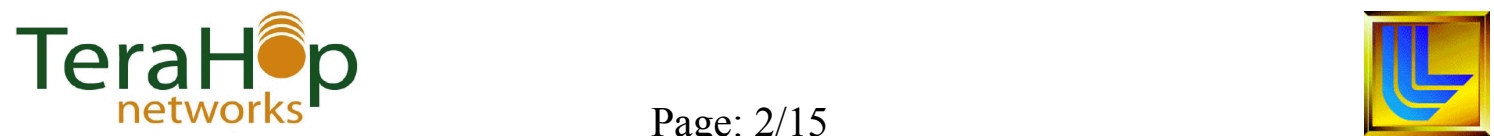


\section{LAWRENCE LIVERMORE NATIONAL LABORATORY}

data collection. The transmission location on the first floor was ultimately chosen for use during the actual exercises because it was accessible to the data collection team during the exercises. This allowed them to remove the hardware once the testing was complete without having to wait for the entire day of exercises to complete.

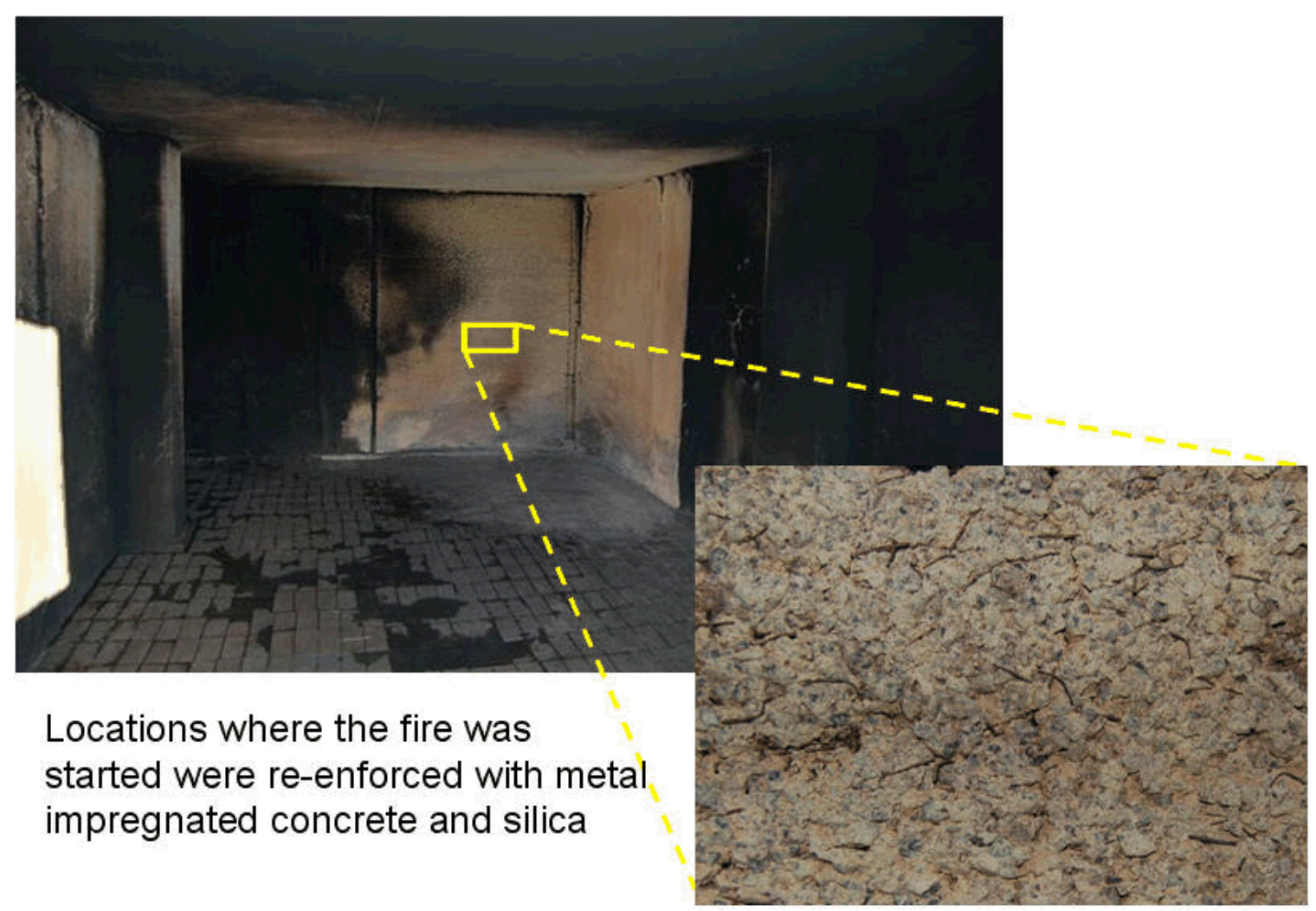

Figure 3: Metal fibers in the wall materials

Unfortunately, RF transmission directly through the central location of the fire on the first floor was not possible, so the transmission path had to be shifted approximately 6' off the side of the fire's center. The corner where the fire was located on the first floor was reenforced with a mixture of concrete and metal fibers for heat resistance. This material was highly reflective, permitting very little RF energy to pass through it. This phenomenon was also observed and verified by Terahop's testing, discussed in the next section. An image of these re-enforced walls and a close up of the actual wall material containing the metal fibers can bee seen in Figure 3 above. 


\section{LAWRENCE LIVERMORE NATIONAL LABORATORY}

\section{Terahop Data Collection and Systems:}

Terahop collected data from two primary test methods. The first test was to perform measurements of how the structure itself and the fire attenuates RF transmissions in the primarily ISM bands $(900 \mathrm{MHz}, 2.4 \mathrm{GHz}$, and $5.8 \mathrm{GHz})$. This was done by placing wideband RF antennas across a corner of the building (transmission directly through the building was not possible due to the power requirements and the metallic reinforced corners where the fire was located). Originally, a network analyzer was evaluated for data collection, but higher power levels were found to be required and the team ultimately ended up using a frequency synthesizer to generate $\mathrm{CW}$ information on the frequencies of interest while quantitatively measuring the received signal strength on a spectrum analyzer. The intent was to measure the loss at the desired frequencies with the building empty and then repeat those measurements with the fire burning to get a quantitative measure of the plasma effects on the frequencies of interest. Figure $\mathbf{4}$ below shows a diagram of the basic antenna placement around the building during measurement and Figure 5 shows the physical equipment setup and the antenna placement during calibration (the antennas were moved between a line-of-sight path for calibration and a path obstructed by the building for measurement).

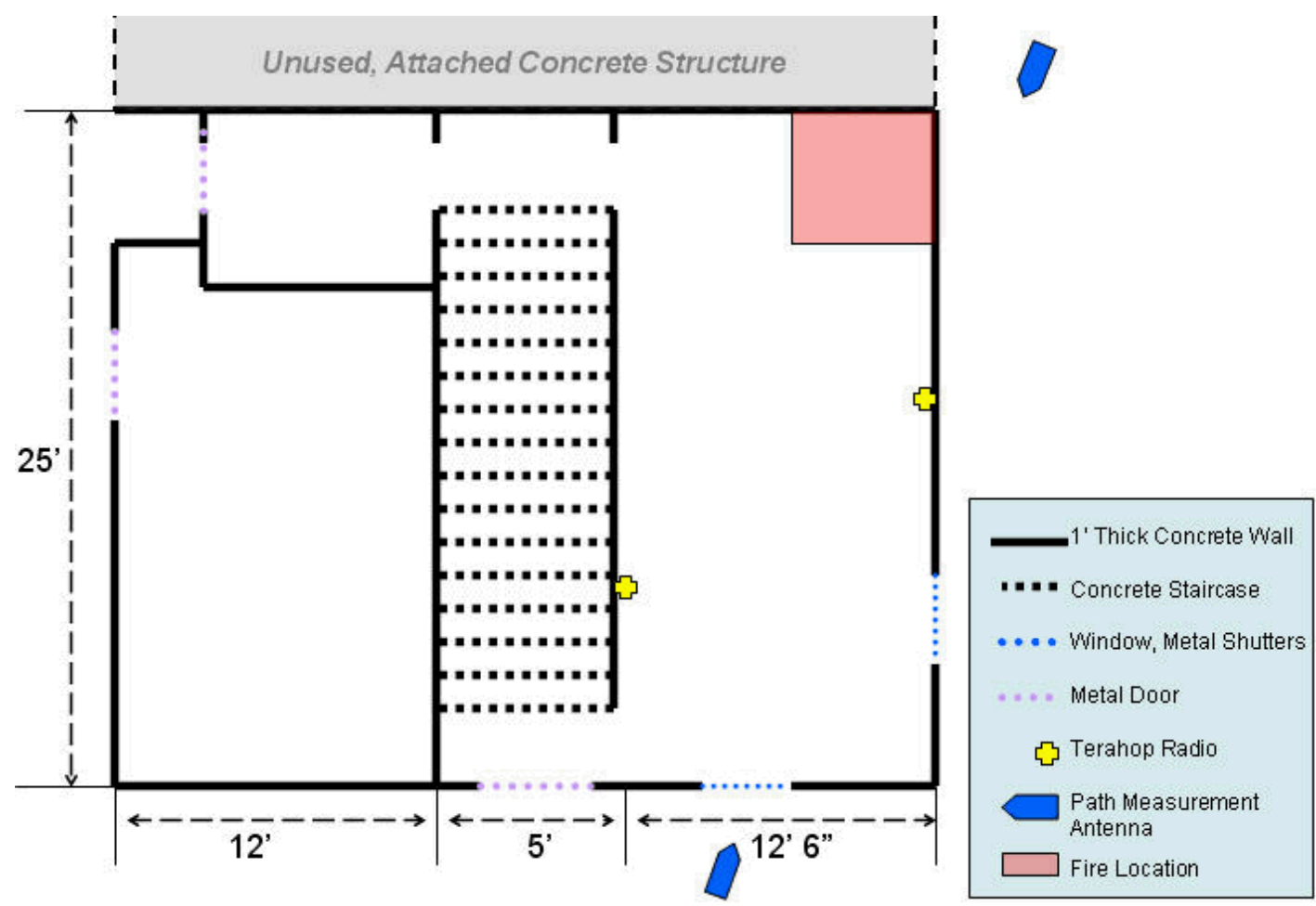

Figure 4: Terahop mote placement and path loss measurement antenna locations 


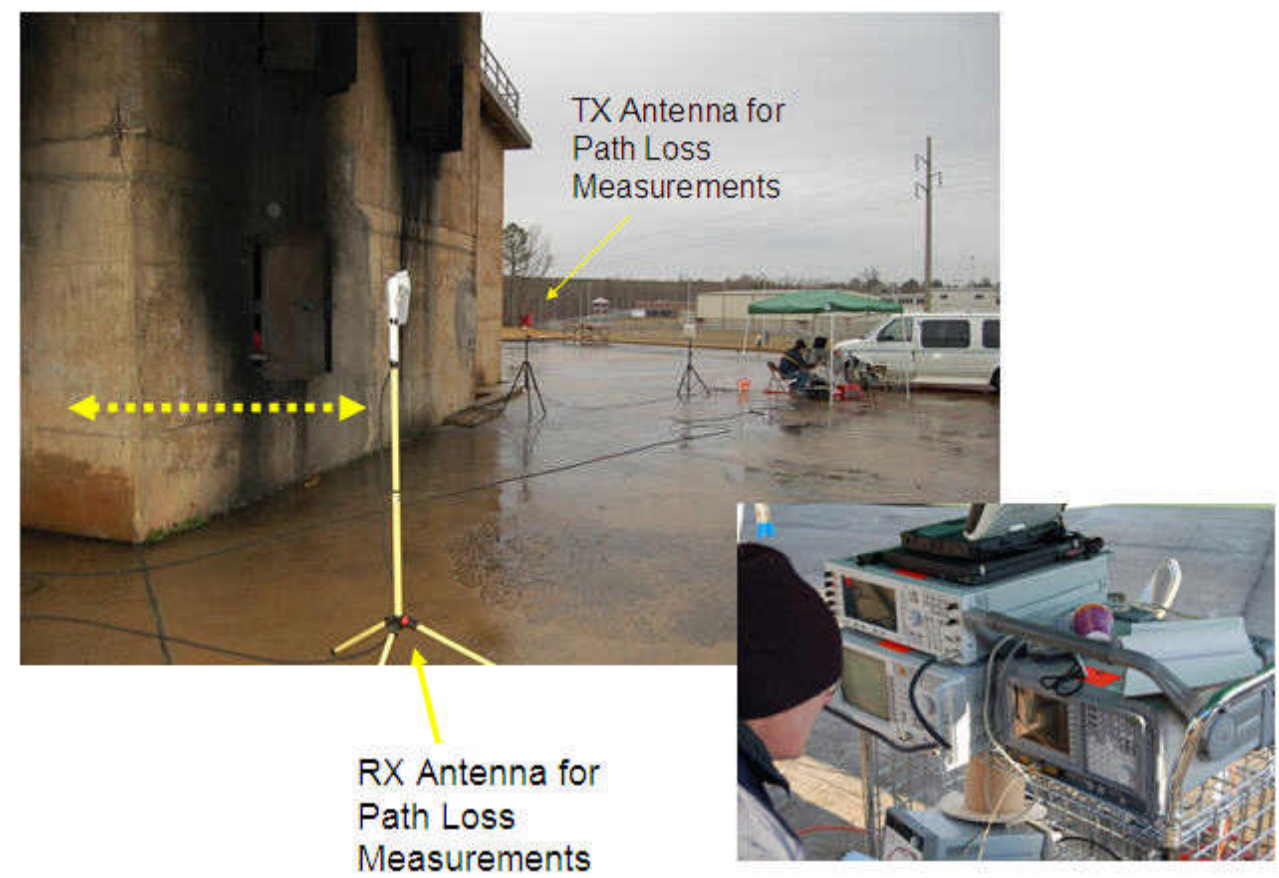

Figure 5: RF path loss and frequency penetration tests

In addition to low level RF path loss measurements, Terahop brought and deployed a number of their wireless motes around on the inside of the building on the first and second floors. Their motes were wrapped in protective thermal enclosures and were scattered throughout the building to test RF connectivity during the exercises. These motes communicated via Bluetooth to gateway antennas deployed around the perimeter of the building. The mote placement locations near the fire on first floor are shown in the diagram in Figure 4. The mote's RF enclosures and exterior mote gateway transceiver can be seen in Figure 6 below.

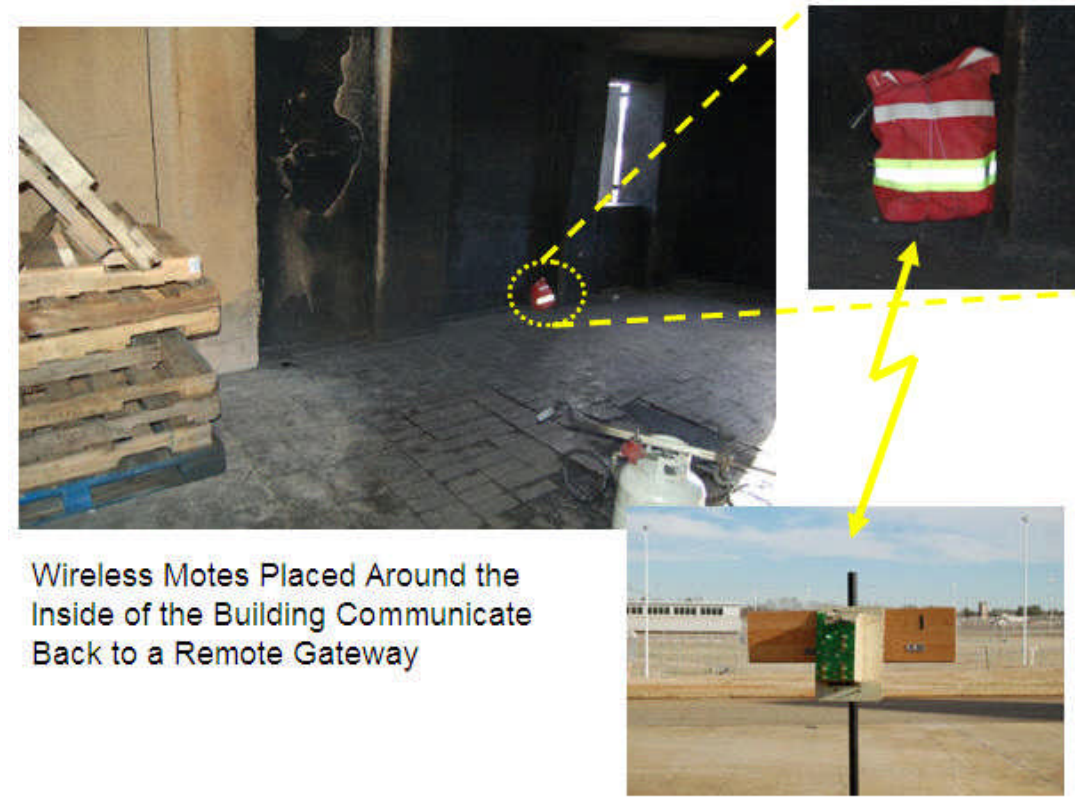

Figure 6: Deployable mote network inside building 


\section{Lawrence Livermore Data Collection:}

In addition to the RF path testing and the mote tests, Lawrence Livermore National Laboratory brought a UWB transmitter-receiver pair setup for collecting bit error rate data. This system consisted of a UWB transmitter centered around $1.6 \mathrm{GHz}$ transmitting approximately $1.6 \mathrm{~mW}$ RMS power spread across a $500 \mathrm{MHz}$ wide bandwidth. The receiver, having no automatic gain control, employed a manual front end attenuator which could be set to add a fixed amount of attenuation to the signal to allow for simulated increases in path loss. The system incorporated no RF or data averaging, CRCs, re-transmissions, data coding or any other error reduction techniques. It was built, and intended, to simply demonstrate the penetration capabilities of narrow time pulses through materials. This system was packaged and deployed as shown below in Figure 7.

Transmitter: 5 ' Above the Ground
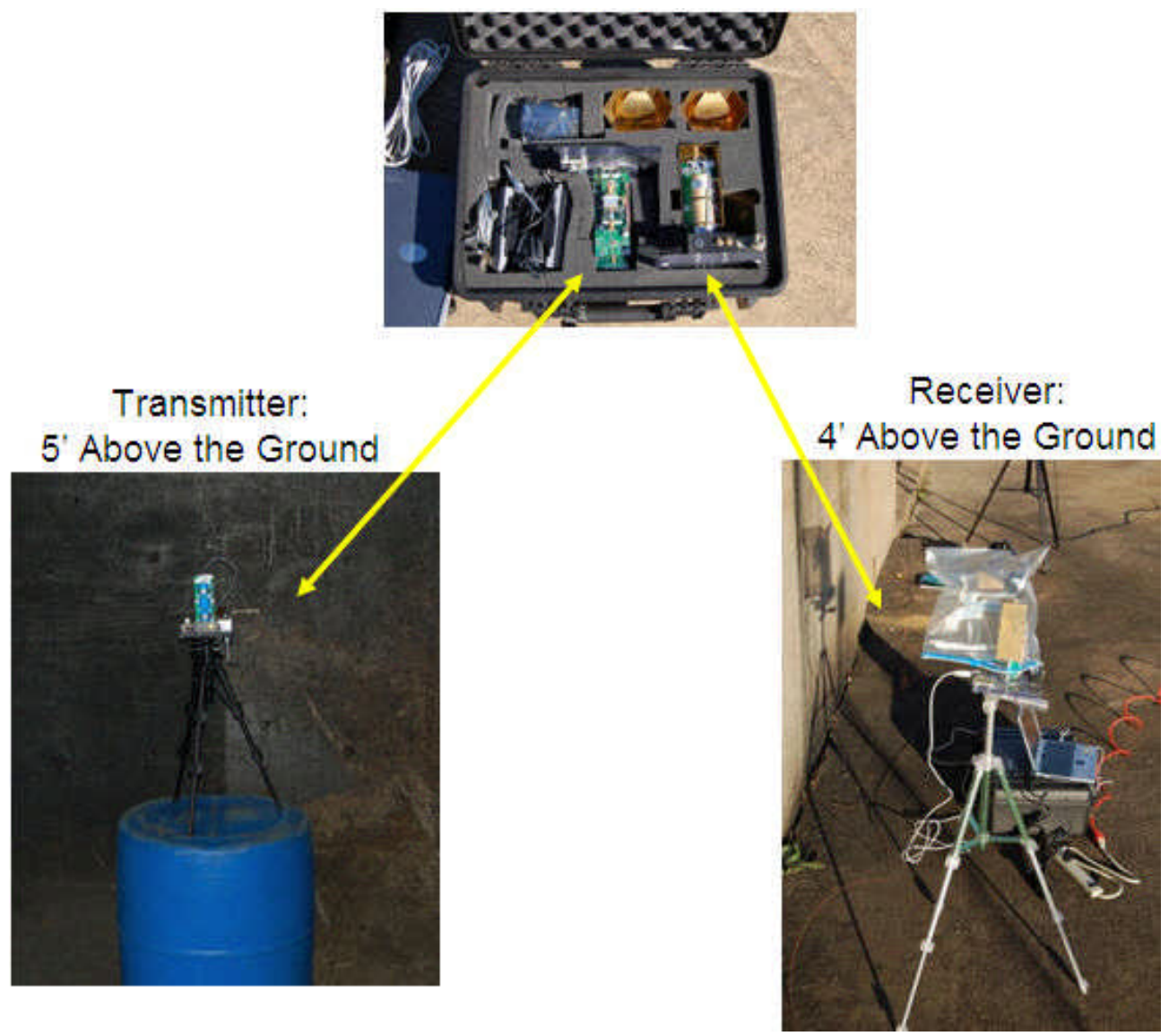

Figure 7: Lawrence Livermore National Laboratory's ultra-wideband bit error rate testing hardware 


\section{LAWRENCE LIVERMORE NATIONAL LABORATORY}

\section{LLNL Deployment Locations:}

As described in the building layout and structure section, this system was tested penetration throughout the first and second floors. In the interests of accessibility and hardware safety, the final deployment location was chosen to be the first floor as detailed in the floor plan diagram, Figure 8, below.

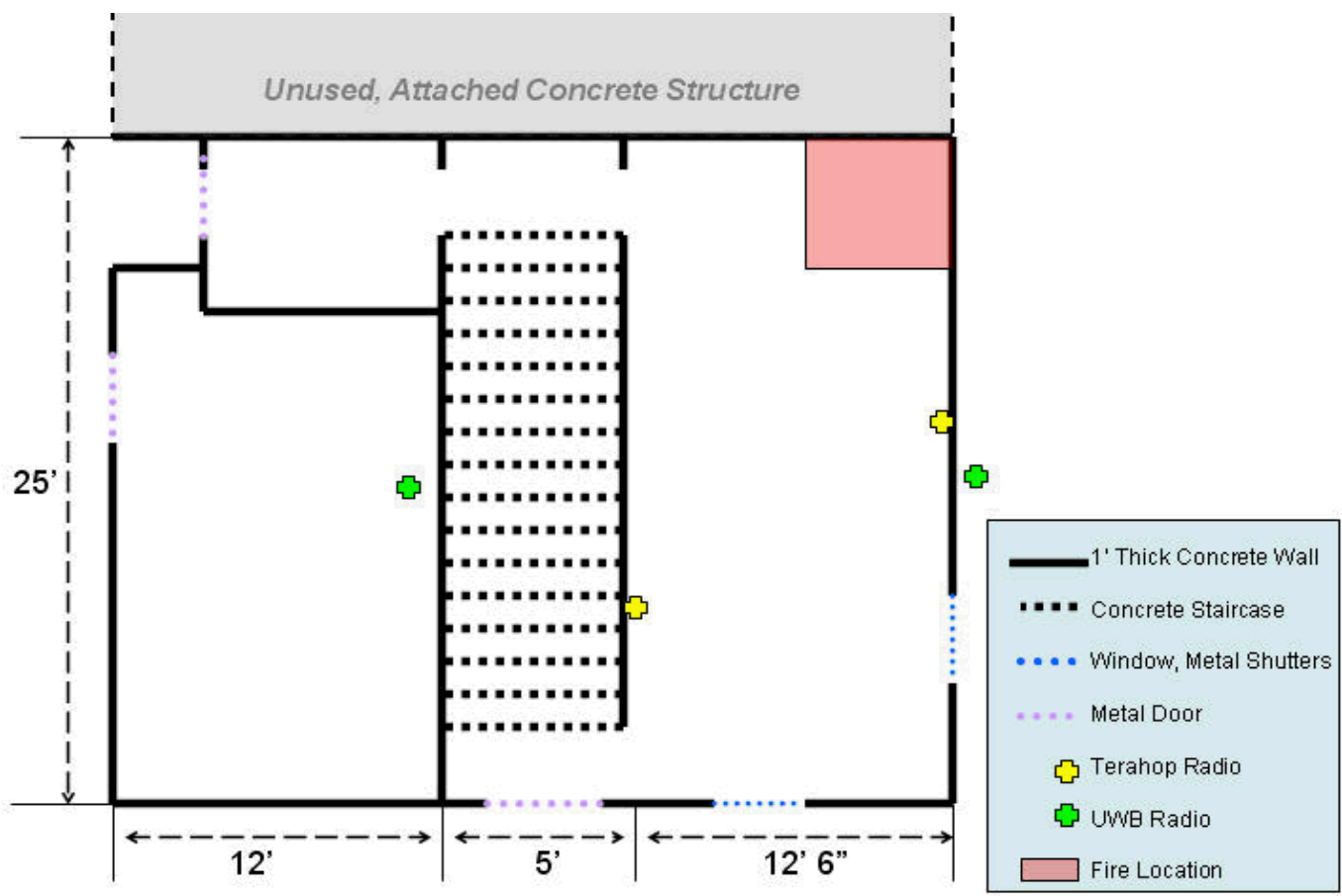

Figure 8: UWB transmitter and receiver placement

The system's receiver was deployed on the exterior wall near the planned fire location and the transmitter was moved around the floor to assess suitable locations that would not pose a heat risk to the equipment or interfere with the training exercises. In testing, the transmitter was found to be able to penetrate three of the 1' thick rebar re-enforced walls allowing it to be placed in an isolated room on the opposite side of the building. It was not capable of penetrating the $4^{\text {th }}$ wall which would have allowed it to be placed completely on the opposite side of the building. Ultimately, the transmitter was placed in an isolated room on the far side of the building which had no windows or doors connecting it to the rest of the building. It only had one exterior door facing the opposite direction of the receiver, and during operation, that metal door was closed eliminating any possibility of multi-path or refraction around the exterior of the building. Figure 9 below shows the actual placement locations of the UWB transmitter and receiver. While their placement locations were kept constant during the actual exercises, in testing the team found they could be moved along their placement walls without major affects on the signal quality. Only when the path was directly blocked by the metal impregnated fire wall near the actual fire location was the signal reduced to a level unusable for bit error rate calculations.

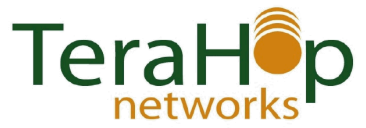




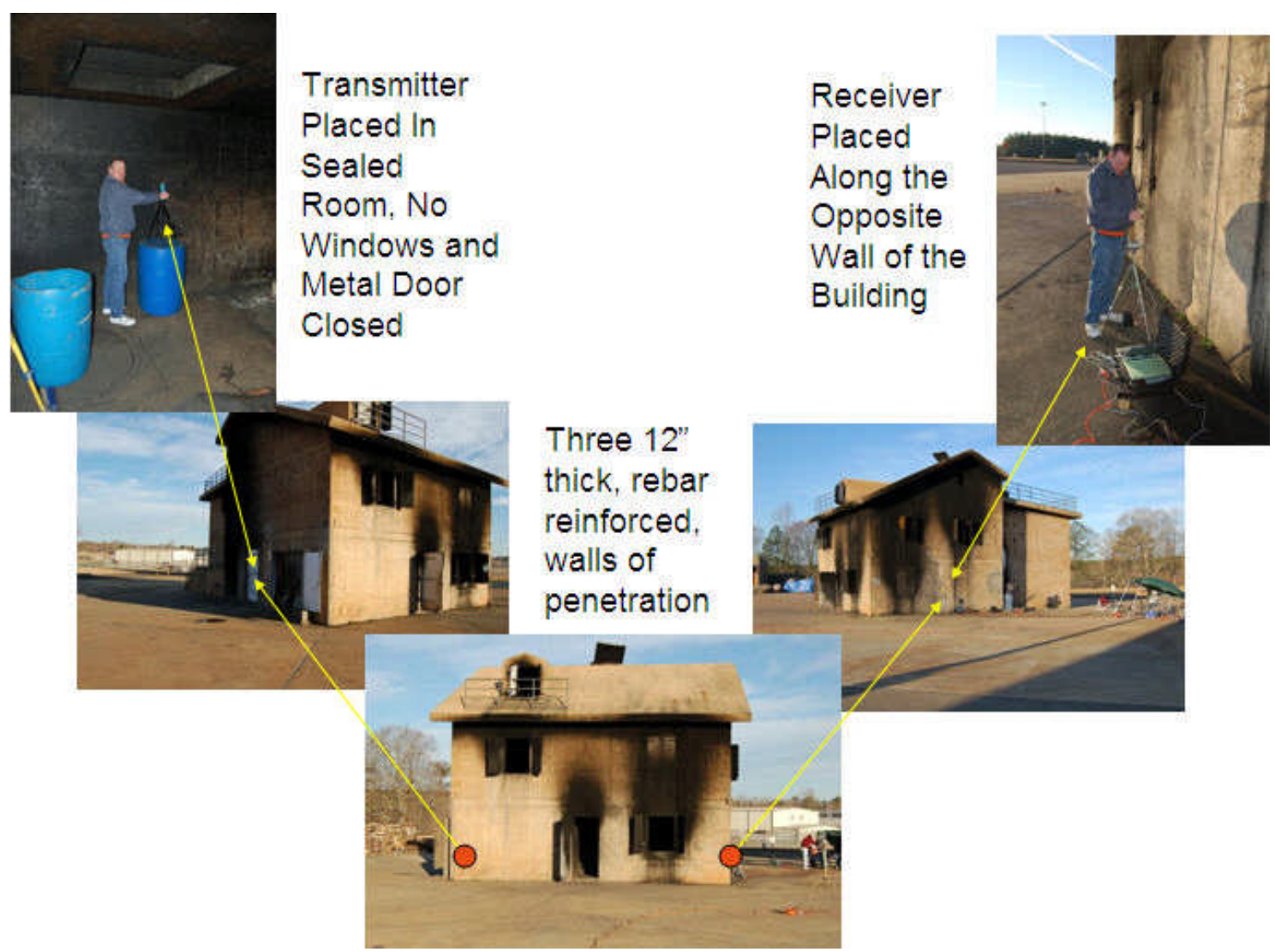

Figure 9: UWB deployment locations

\section{Empty Building Tests:}

Once the transmitter and receiver were setup in suitable out of the way locations, bit error rate data was collected from them with the building empty and all metal doors and shutters closed. Sets of $10^{6}$ data bits were collected, and processed for errors. Then, using the manual attenuator, attenuation was added in $1 \mathrm{~dB}$ increments until the bit error rate was nearly $100 \%$. The results of this data collection in the empty building are plotted below. 100 sample sets of 10kbit data bursts were collected in time and are plotted across the $\mathrm{X}$-axis (totaling $10^{6}$ bits) with the percentage of bits received in error on the $\mathrm{Y}$-axis. Various spikes in the data during given frames indicate either the presence of interference at that time or some change in the RF path causing the loss of data during that time. 
LAWRENCE LIVERMORE NATIONAL LABORATORY

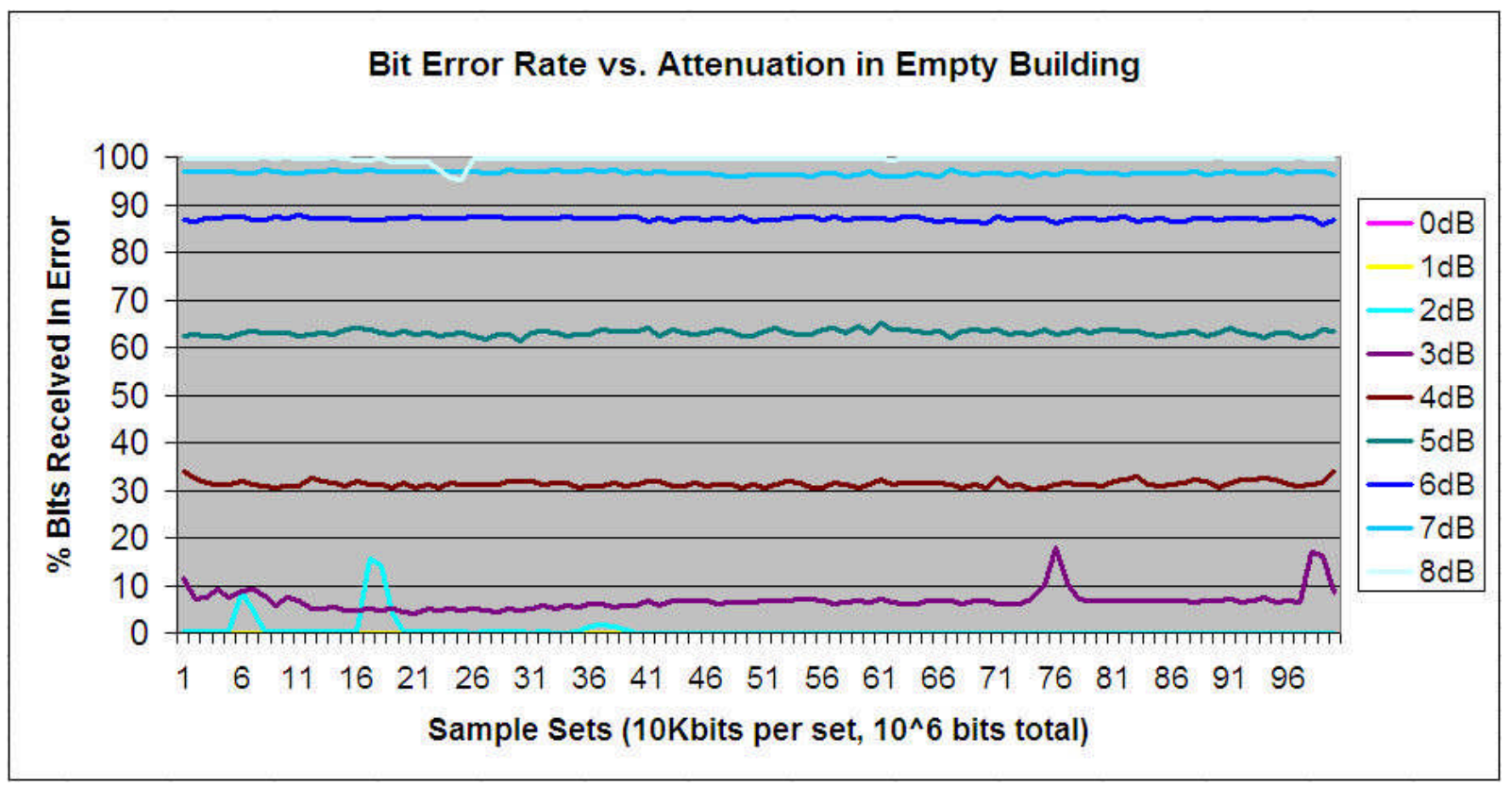

Figure 10: Bit error rate, empty building

By correlating what data was received to the data the system knows is being transmitted, we are able to determine how many bits were received in error because of data loss (the RF emanation was not picked up by the receiver), and how many bits were received in error because of interference (environmental RF emissions causing additional data to be received when it was not actually transmitted). These results can be seen in Table 1 below. As the front-end RF attenuation on the receiver is increased, the bit errors transition to being completely caused by RF data loss, as expected.

\begin{tabular}{|l|l|l|}
\hline $\begin{array}{l}\text { Attenuation } \\
\text { Level: }\end{array}$ & $\begin{array}{l}\text { Errors From } \\
\text { Data Loss: }\end{array}$ & $\begin{array}{l}\text { Errors From } \\
\text { Interference: }\end{array}$ \\
\hline 0dB & $0 \%$ & $0 \%$ \\
\hline $\mathbf{1 d B}$ & $100 \%$ & $0 \%$ \\
\hline $\mathbf{2 d B}$ & $24.43 \%$ & $75.57 \%$ \\
\hline $\mathbf{3 d B}$ & $94.23 \%$ & $5.77 \%$ \\
\hline $\mathbf{4 d B}$ & $99.6 \%$ & $0.4 \%$ \\
\hline $\mathbf{5 d B}$ & $99.99 \%$ & $0.001 \%$ \\
\hline $\mathbf{6 d B}$ & $100 \%$ & $0 \%$ \\
\hline $\mathbf{7 d B}$ & $100 \%$ & $0 \%$ \\
\hline $\mathbf{8 d B}$ & $100 \%$ & $0 \%$ \\
\hline
\end{tabular}

Table 1: Bit error breakdown for empty building 


\section{Burn Cycle and Fire Tests:}

Following the test with the empty building, the firefighting exercises were commenced. For those exercises, large fires were started on the first and second floors using wooden pallets. The fires were built, ignited, allowed to grow to substantial size, and then trainees were instructed on how to properly extinguish them using conventional fire hoses. Once extinguished, the fires were re-built and the process was started all over again. Example images from various stages of this process can be seen in Figure 11 below. The process continued all day as various groups of firefighters where instructed and practiced their skills. In the morning only the fire on the first floor was utilized, in the afternoon fires on both floors were ignited and used for training.

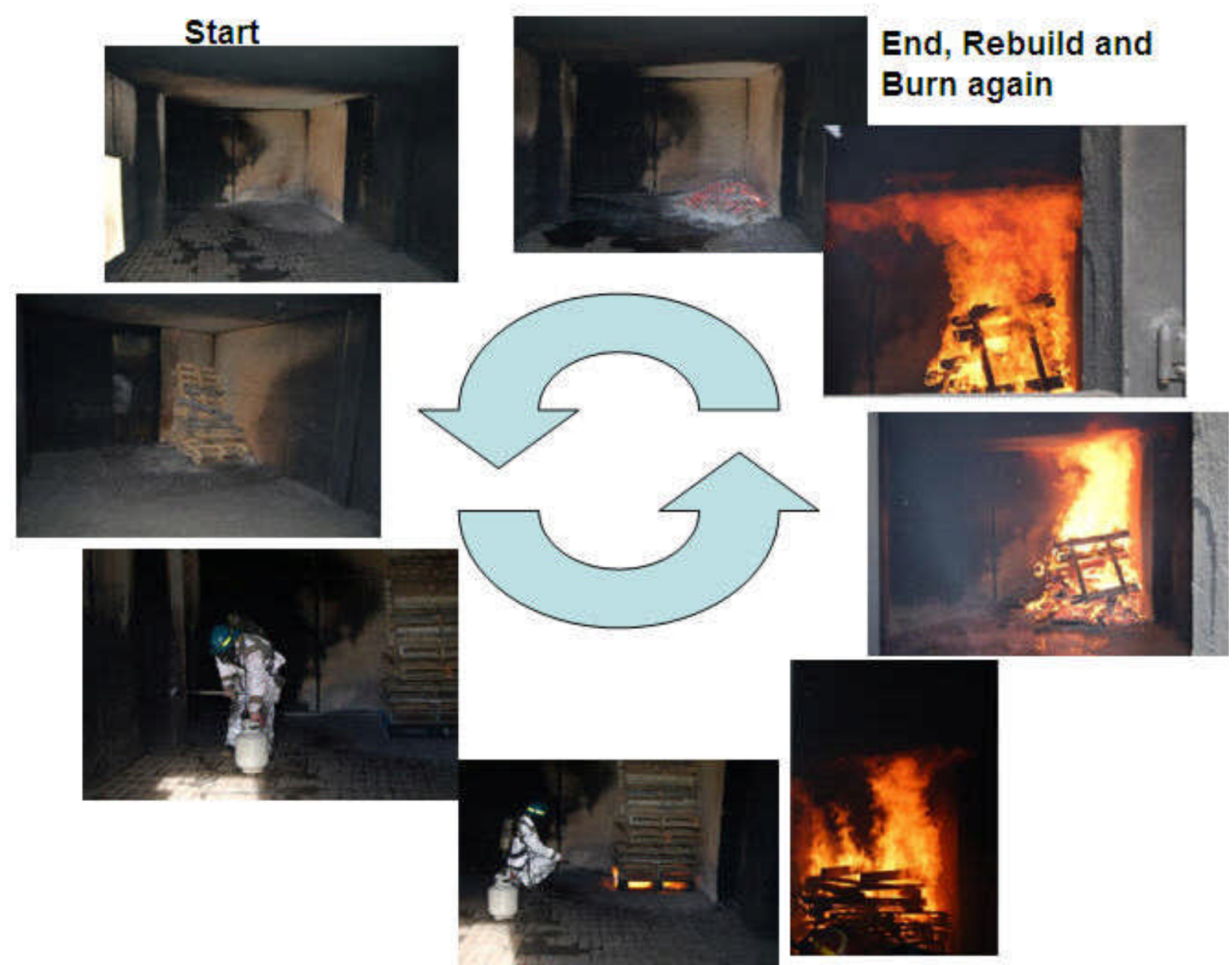

Figure 11: Fire ignition, training extinguishment, and re-ignition cycle

During the burn times these fires were allowed to get quite large, filling the room with flames which ran along the ceiling and generated high temperature plasmas near the ceiling $>700^{\circ} \mathrm{F}$. When the fires were first built, and allowed to reach temperature, we collected another set of bit error rate data using the UWB hardware. The results of this test can be seen in the plot below.

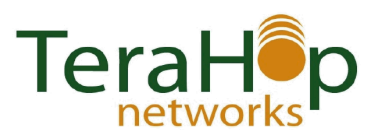




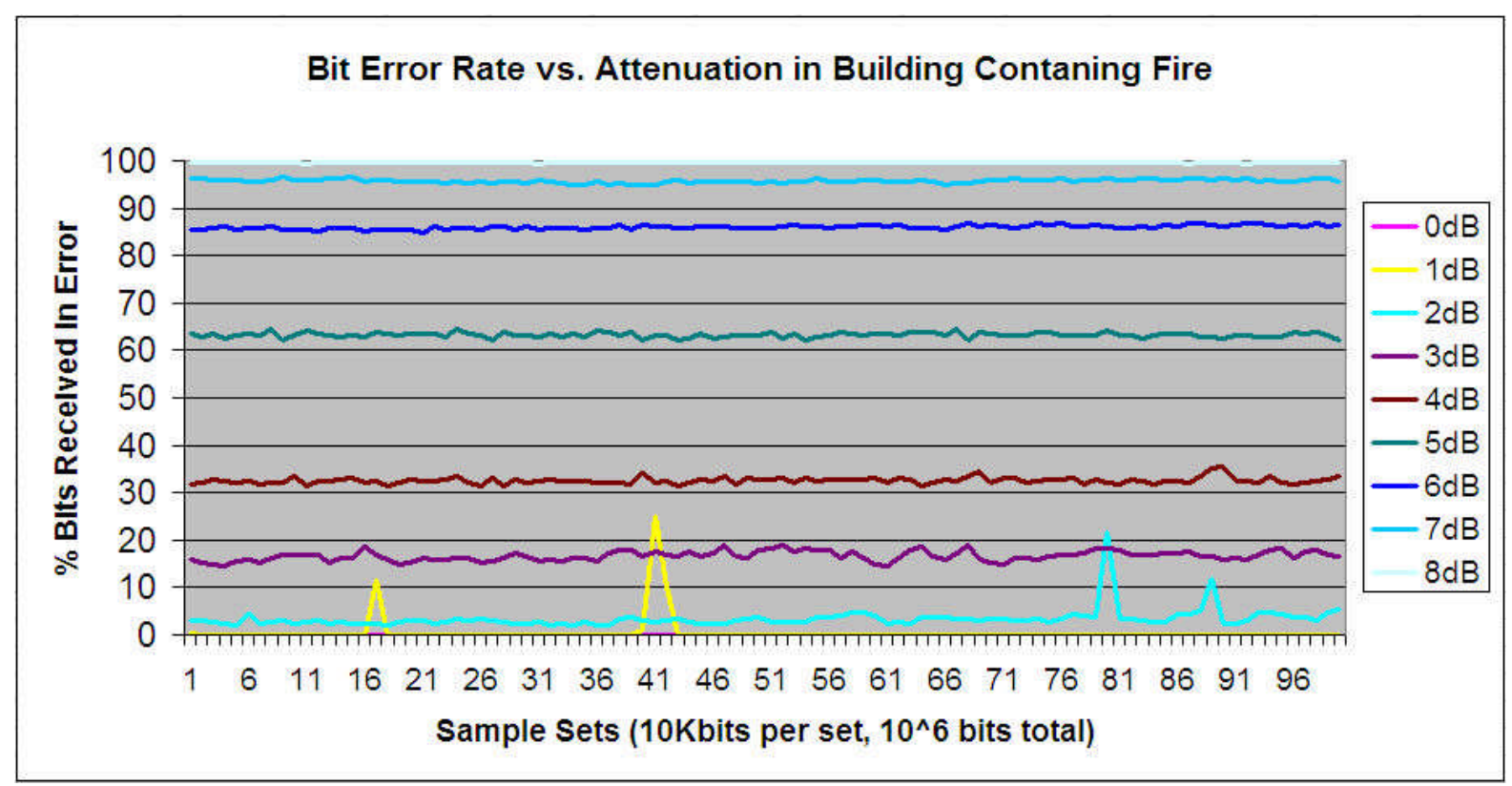

Figure 12: Bit error rate, empty building with fire burning

As before, by correlating what data was received to the data the system knows is being transmitted, we are able to determine how many bits were received in error because of data loss and how many bits were received in error because of interference. These results can be seen in Table 2 below. By comparing the empty building data to the data collected with the fire burning you can see little change in the overall bit-error-rates, or percentage of data lost due to any RF interference generated by the fire. However, it is possible that the RF path did not travel through enough of the fire, or that the fire never became hot enough to generate plasma that would affect the RF path.

\begin{tabular}{|l|l|l|}
\hline $\begin{array}{l}\text { Attenuation } \\
\text { Level: }\end{array}$ & $\begin{array}{l}\text { Errors From } \\
\text { Data Loss: }\end{array}$ & $\begin{array}{l}\text { Errors From } \\
\text { Interference: }\end{array}$ \\
\hline 0dB & $100 \%$ & $0 \%$ \\
\hline $\mathbf{1 d B}$ & $0 \%$ & $100 \%$ \\
\hline $\mathbf{2 d B}$ & $91.46 \%$ & $8.54 \%$ \\
\hline $\mathbf{3 d B}$ & $100 \%$ & $0 \%$ \\
\hline $\mathbf{4 d B}$ & $99.66 \%$ & $0.34 \%$ \\
\hline $\mathbf{5 d B}$ & $99.99 \%$ & $0.009 \%$ \\
\hline $\mathbf{6 d B}$ & $100 \%$ & $0 \%$ \\
\hline $\mathbf{7 d B}$ & $100 \%$ & $0 \%$ \\
\hline $\mathbf{8 d B}$ & $100 \%$ & $0 \%$ \\
\hline
\end{tabular}

Table 2: Bit error breakdown for empty building with fire burning 


\section{Morning Training Exercises and Tests:}

After collection of the fire bit error rate data, groups of approximately 15 trainee firefighters were allowed to enter the building for instruction and practice. Once inside they were instructed how to properly assess and extinguish the fire, then they each took turns extinguishing the fire. Once complete, the fire was rebuilt and another group of trainees entered the building for the same instruction and practice. In the morning these exercises were limited to the first floor. All trainee groups would enter through the door on the front of the building, as shown below in Figure 13, and then gather in the room with the fire in it on the right side of the building (directly in the RF path of the UWB bit error rate system). During one of these training sessions, with the room full of trainees, we collected another set of bit error rate data which is presented below.

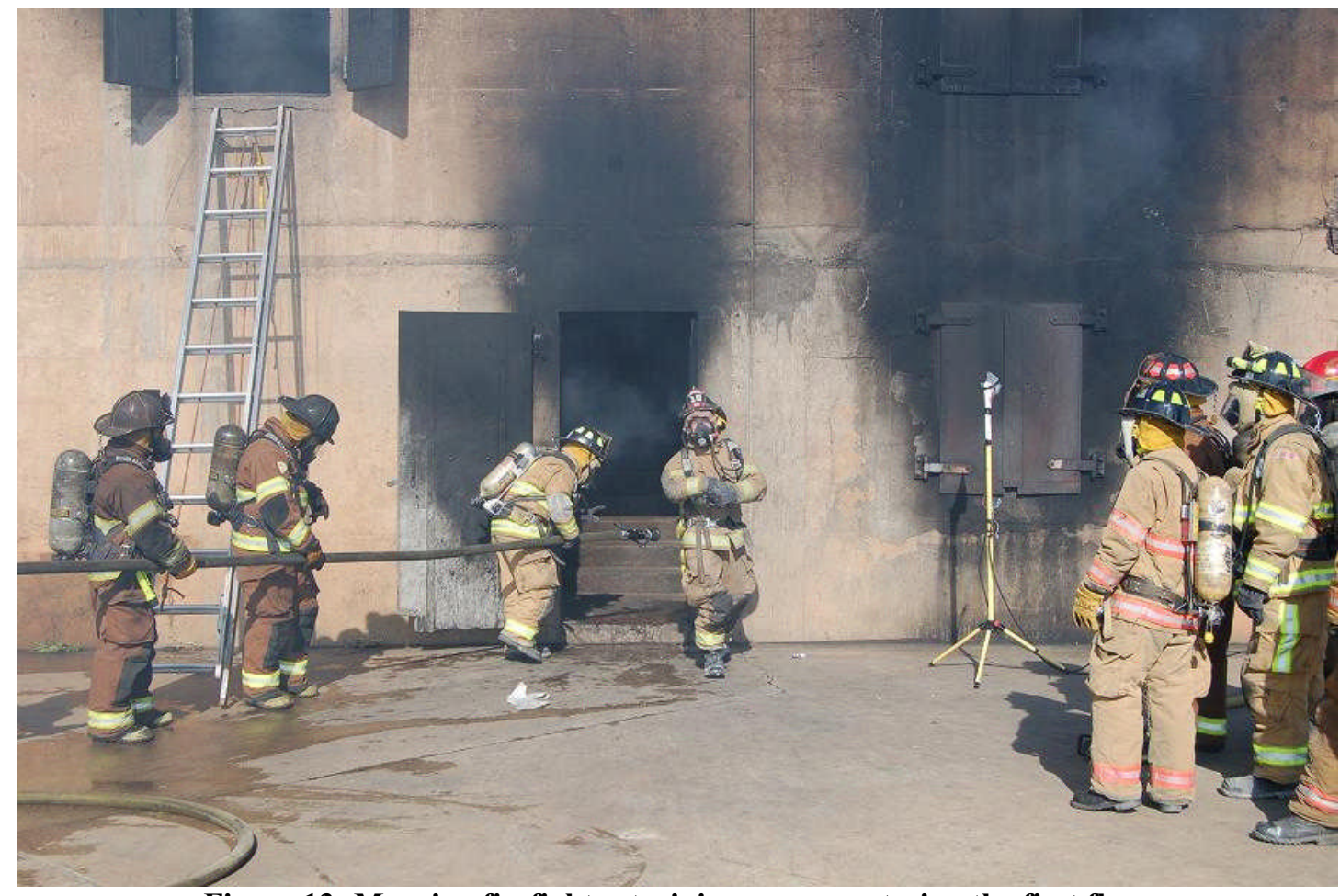

Figure 13: Morning firefighter training groups entering the first floor

During these sessions, typically 10-20 students were gathered in the room directly between the UWB transmitter and receiver in addition to the burning fire. Each student was equipped with a radio for communication with the instructor and other firefighters which was in operation during the data collection. In addition, during data collection the fire was also extinguished using the fire hose, a process which covered the floor and walls with water. The resulting bit error rate during these activities can be seen in the plot below. 
LAWRENCE LIVERMORE NATIONAL LABORATORY

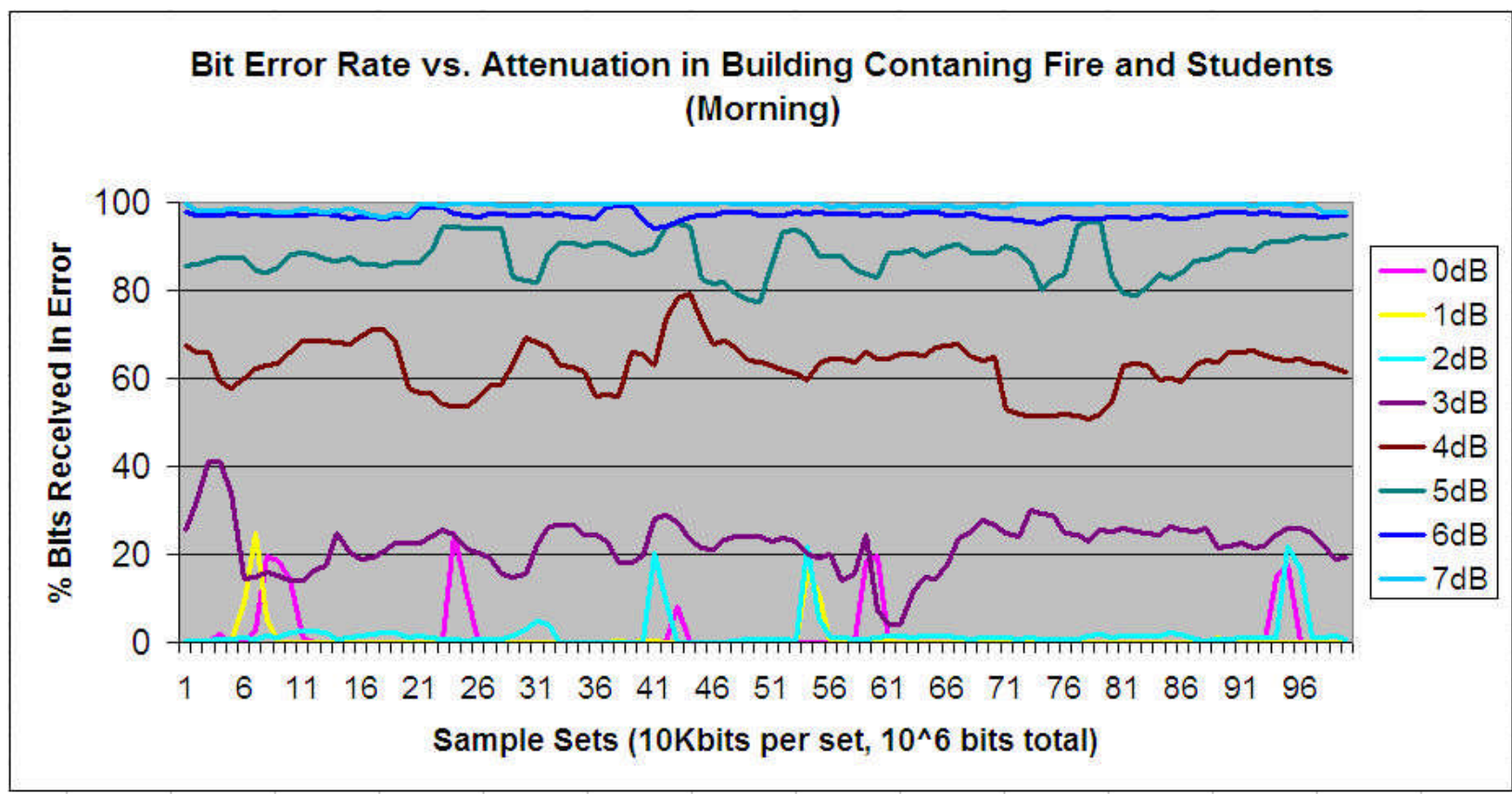

Figure 14: Bit error rate, occupied building with first floor fire burning

As before, by correlating what data was received to the data the system knows is being transmitted, we are able to determine how many bits were received in error because of data loss and how many bits were received in error because of interference. These results can be seen in Table 3 below. From the plot in Figure 14 and Table 3 you can see that the introduction of several people moving around and communicating using radios added considerable variation to the bit-error-rate of the system. However, the variation is not always negative, and the average bit error rate across the collection period can be seen to be nearly identical to the data collected in the empty building test case, and the empty building with the fire burning test. This is most likely because, while the added RF interference from their radios hurts the bit error rate, the addition of several people to the environment provides for multiple RF paths for the signal to make it through.

\begin{tabular}{|l|l|l|}
\hline $\begin{array}{l}\text { Attenuation } \\
\text { Level: }\end{array}$ & $\begin{array}{l}\text { Errors From } \\
\text { Data Loss: }\end{array}$ & $\begin{array}{l}\text { Errors From } \\
\text { Interference: }\end{array}$ \\
\hline $\mathbf{0 d B}$ & $32.78 \%$ & $67.22 \%$ \\
\hline $\mathbf{1 d B}$ & $5.97 \%$ & $94.03 \%$ \\
\hline $\mathbf{2 d B}$ & $53.03 \%$ & $46.97 \%$ \\
\hline $\mathbf{3 d B}$ & $98.8 \%$ & $1.2 \%$ \\
\hline $\mathbf{4 d B}$ & $99.94 \%$ & $0.06 \%$ \\
\hline $\mathbf{5 d B}$ & $100 \%$ & $0 \%$ \\
\hline $\mathbf{6 d B}$ & $100 \%$ & $0 \%$ \\
\hline $\mathbf{7 d B}$ & $100 \%$ & $0 \%$ \\
\hline
\end{tabular}

Table 3: Bit error breakdown for occupied building with first floor fire burning 


\section{LAWRENCE LIVERMORE NATIONAL LABORATORY}

\section{Afternoon Training Exercises and Tests:}

In the afternoon, the first floor doorway was closed off and an additional fire was started on the second floor. Trainees were required to enter the building through a second floor window and then, once in side, extinguish both the first and second floor fires before exiting the building via the second floor window again. A training group entering the building to perform this task can be seen in Figure 15 below. During these training sessions we collected another, final, set of bit error rate data which is presented below in Figure 16 and Table 4.

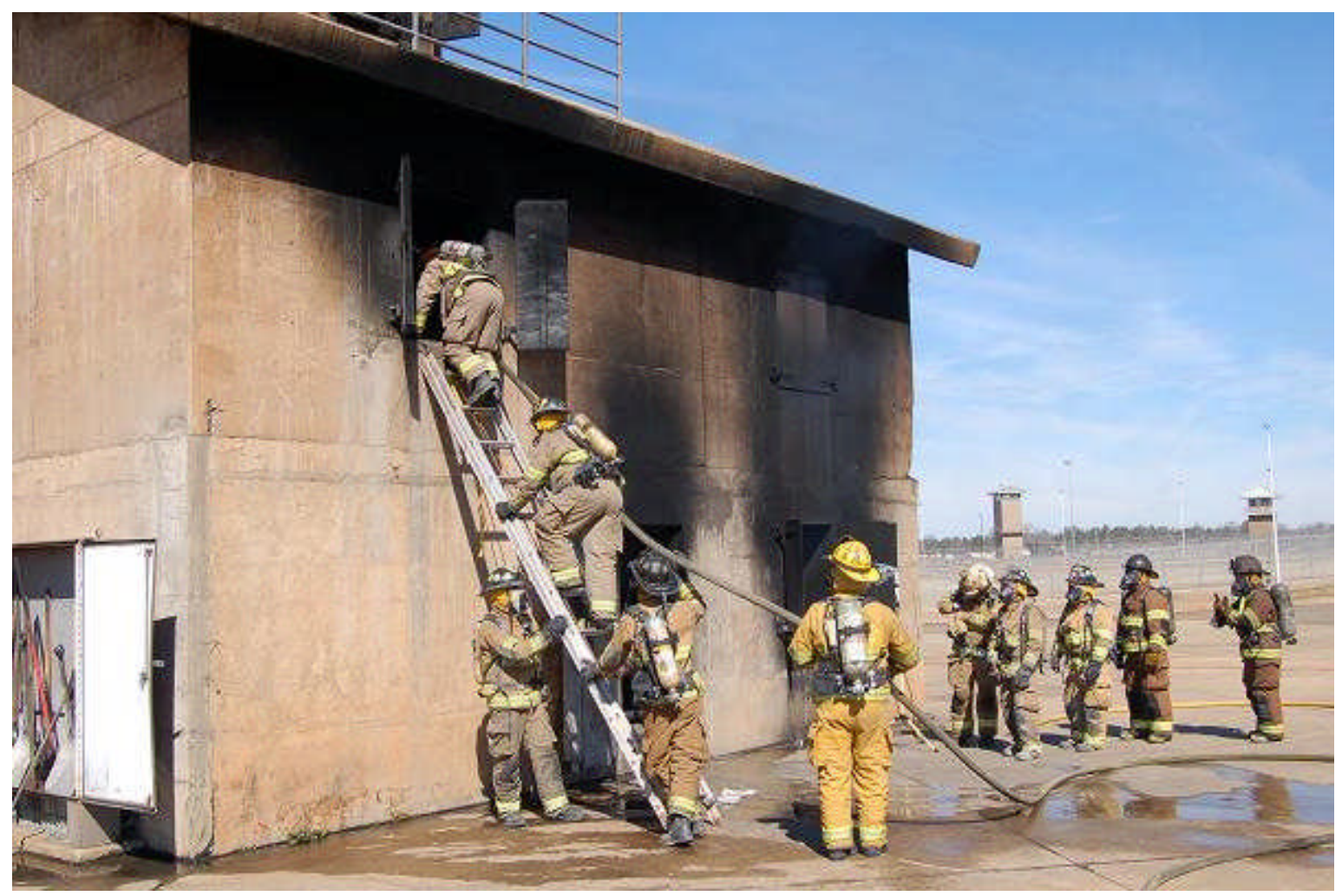

Figure 15: Afternoon firefighter training groups entering the second floor 
LAWRENCE LIVERMORE NATIONAL LABORATORY

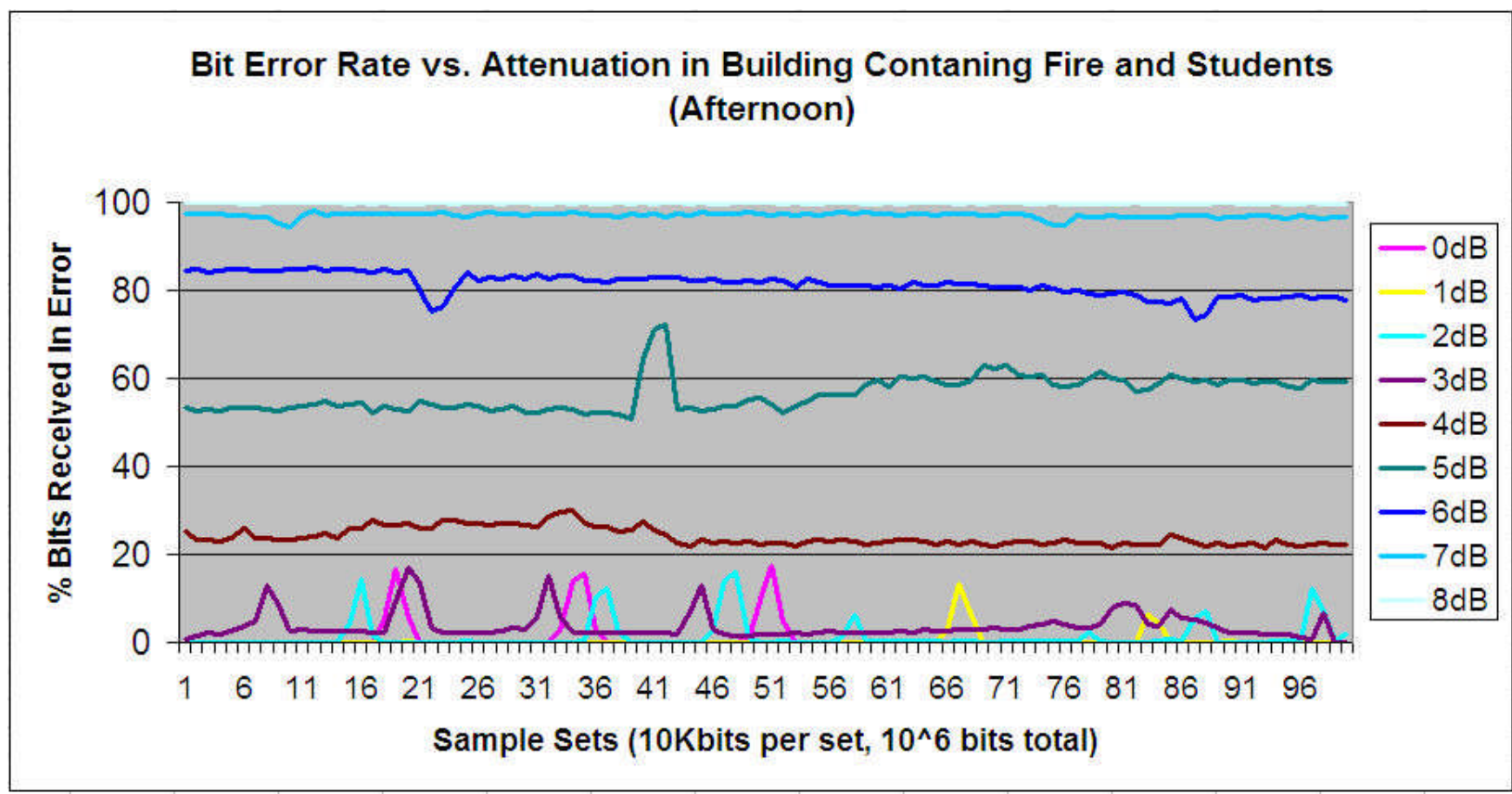

Figure 16: Bit error rate, occupied building with first and second floor fires burning

As in the morning case, you can see that the introduction of several people moving around and communicating using radios added some variation to the bit-error-rate of the system. However, the variation is not always negative and in this case, when the trainees are spread throughout the building, the average bit error rate is less than in the morning case when they were all directly located in the RF path.

\begin{tabular}{|l|l|l|}
\hline $\begin{array}{l}\text { Attenuation } \\
\text { Level: }\end{array}$ & $\begin{array}{l}\text { Errors From } \\
\text { Data Loss: }\end{array}$ & $\begin{array}{l}\text { Errors From } \\
\text { Interference: }\end{array}$ \\
\hline 0dB & $0.74 \%$ & $99.26 \%$ \\
\hline $\mathbf{1 d B}$ & $6.9 \%$ & $93.1 \%$ \\
\hline $\mathbf{2 d B}$ & $12.26 \%$ & $87.74 \%$ \\
\hline $\mathbf{3 d B}$ & $74.96 \%$ & $25.04 \%$ \\
\hline $\mathbf{4 d B}$ & $99.71 \%$ & $0.29 \%$ \\
\hline $\mathbf{5 d B}$ & $99.99 \%$ & $0.01 \%$ \\
\hline $\mathbf{6 d B}$ & $99.999 \%$ & $0.001 \%$ \\
\hline $\mathbf{7 d B}$ & $100 \%$ & $0 \%$ \\
\hline $\mathbf{8 d B}$ & $100 \%$ & $0 \%$ \\
\hline
\end{tabular}

Table 4: Bit error breakdown for occupied building with first and second floor fires burning 